\title{
Does feigning amnesia impair subsequent recall?
}

\author{
Xue Sun, Paawan V. Punjabi, Lucy T. Greenberg, and John G. Seamon \\ Wesleyan University, Middletown, Connecticut
}

\begin{abstract}
Defendants who are accused of serious crimes sometimes feign amnesia to evade criminal responsibility. Previous research has suggested that feigning amnesia might impair subsequent recall. In two experiments, participants read and heard a story about a central character, described as "you," who was responsible for the death of either a puppy (Experiment 1) or a friend (Experiment 2). On free and cued recall tests immediately after the story, participants who had feigned amnesia recalled less than did participants who had recalled accurately. One week later, when all participants recalled accurately, participants who had previously feigned amnesia still performed worse than did participants who had recalled accurately both times. However, the participants who had formerly feigned amnesia did not perform worse than did a control group who had received only the delayed recall tests. Our results suggest that a "feigned amnesia effect" may reflect nothing more than differential practice at recall. Feigning amnesia for a crime need not impair memory for that crime when a person later seeks to remember accurately.
\end{abstract}

When called to testify about illegal actions, individuals may attempt to avoid perjury and evade responsibility for their previous actions by claiming that they cannot remember. These claims of "focal retrograde amnesia," whereby individuals report a relatively isolated, permanent memory loss for autobiographical events associated with a specific crime, can occur at rates of $25 \%-45 \%$ when defendants are charged with murder (Kopelman, 1995). Because genuine cases of focal retrograde amnesia in neurological patients are rare, researchers suspect that many defendants who present this memory problem when charged with a crime are actually feigning amnesia to avoid legal responsibility, especially when they face substantial incriminating evidence (see Cercy, Schretlen, \& Brandt, 1997; Pyszora, Barker, \& Kopelman, 2003; Rubinsky \& Brandt, 1986; and Schacter, 1986, for reviews). In many of these instances, the individuals claim that the memory loss was due to their use of alcohol or drugs.

Research on feigned amnesia has explored different dimensions of this issue. Some researchers have compared people simulating memory impairments with actual braininjured, amnesic patients. These studies reveal that people feigning amnesia often overplay their assumed impairment and perform worse on memory tests than do genuine amnesic patients (see, e.g., Greiffenstein, Baker, \& Gola, 1994; Wiggins \& Brandt, 1988). Other researchers have employed various diagnostic measures to differentiate genuine from feigned amnesia. On the basis of the idea that people with severe memory impairments will perform at chance on forced choice recognition tests, people feigning amnesia often betray their actual memory abil- ity by performing worse than chance (see, e.g., Bernard, McGrath, \& Houston, 1994; Jelicic, Merckelbach, \& Van Bergen, 2004; Van Oorsouw \& Merckelbach, 2006). Although research on diagnostic measures continues, there is still — as Cercy et al. (1997) previously noted - no "gold standard" measure for distinguishing between cases of genuine and feigned amnesia.

Still other researchers have sought to determine whether feigning amnesia has consequences for later remembering. Specifically, researchers have asked if faking amnesia at one time could impair a person's ability to remember accurately at a later time. Laboratory studies with college students (who have presumably never committed any violent crimes) are informative on this issue. In one early study, Christianson and Bylin (1999) had two groups of college students read a story in which the central character, described as "you," went drinking with a friend, later robbed an elderly couple, and, during the robbery, stabbed the elderly man twice. After a 30-min delay, the participants were told to imagine that the police had arrested them and that they had to report what they remembered. Half of the participants were instructed to respond accurately, and the other half were instructed to evade responsibility by claiming that they could not remember the event due to their drinking. All participants took a free recall test followed by a cued recall test of the story. One week later, the tests were repeated, but this time all participants were instructed to remember as accurately as possible.

Christianson and Bylin (1999) found that participants who feigned amnesia on the initial free and cued recall tests recalled less than did participants who had been instructed 
to recall accurately. One week later, when everyone tried to recall accurately, the participants who had previously faked amnesia showed enhanced recall on both measures, but their performance remained below that of participants who had responded accurately both times. These researchers concluded that feigning amnesia has inhibitory consequences for memory because it impairs subsequent recall. However, as Christianson and Bylin noted, the better recall of the accurate participants on the delayed tests than of the participants who had previously feigned amnesia could have been due to either the inhibitory consequences of previously faking amnesia or, more simply, practice at recalling the facts of the story correctly. Participants in the accurate condition had more practice recalling correctly than did participants in the feigned amnesia condition, and research on repeated recall indicates that recall repetition enhances accuracy (see, e.g., Mulligan, 2005).

Bylin and Christianson (2002) addressed this issue in a follow-up study in which they added a necessary control condition. They presented college students with a story in which the participants imagined themselves as the main character in a story involving a person who was drinking, drove a car too fast, and hit and killed a young woman. Four groups of participants were tested by free and cued recall. After reading the story, one group was told to feign amnesia by claiming a lack of memory (i.e., produce omission errors), whereas a second group was instructed to feign amnesia by misremembering details of the story (i.e., produce commission errors). A third group was instructed to recall accurately, and a fourth group was not tested. The fourth group served as a control condition to provide a performance baseline for the two feigned amnesia groups on the delayed tests. All groups were tested 1 week later with instructions to recall accurately, but these researchers obtained different results for free and cued recall. For free recall, the two groups that had previously faked amnesia showed improved recall that approximated the level of the control group, suggesting that previously feigning amnesia produced no memory impairment. For cued recall, however, all four groups performed similarly highly, showing a ceiling effect that made it difficult to discern any possible consequences of feigning amnesia.

Van Oorsouw and Merckelbach (2004) adopted the appropriate delayed test control condition in their study of feigned amnesia. They had college students read a story involving the violent rape and murder of a friend. The central character, described as "you," later visited a bar, drank, and met the killer, who boasted of his crime. After reading the story, the participants engaged in an actual mock crime in which they entered a bar, picked up a pool cue, and attacked and "killed" a dummy that represented the murderer. After the attack, the participants returned to the lab and were asked to imagine that they had been arrested for murder. As in the previous studies, participants were tested by free and cued recall. One group was told to minimize responsibility for killing the murderer by claiming great difficulty remembering what happened; a second group was instructed to cooperate and recall accurately; and the control group was not tested. One week later, all three groups received the memory tests with instructions to recall accurately. On the initial free and cued recall tests, these researchers found that participants feigning amnesia recalled less than did participants recalling accurately. On the delayed tests, the participants who had previously feigned amnesia improved, but not to the level of the participants who had recalled accurately both times. Moreover, on the delayed free and cued recall tests, the participants who had formerly feigned amnesia did not show worse recall than the control group who had recalled accurately on both tests for the first time. Van Oorsouw and Merckelbach (2004) concluded that although feigned amnesia can impair memory for a crime, this effect is likely based on group differences in recall practice. A simpler interpretation of these results is that there is little support for the hypothesis that feigning amnesia impairs subsequent recall.

Finally, Van Oorsouw and Merckelbach (2006) had college student participants engage in a different actual mock crime. In this experiment, participants entered a bar, tied someone up with a rope, and robbed the bar. When participants were tested after the crime and again 1 week later, those who had been initially instructed to fake amnesia recalled less at both times than did participants who had recalled accurately. These results are similar to those observed by Christianson and Bylin (1999), but, like Christianson and Bylin's study, this study lacked the appropriate control condition of a delay-only recall condition, making the results problematic in their interpretation.

In summary, a well-defined procedure exists for testing the effect of feigned amnesia on subsequent recall. Participants who read or otherwise engage in actions about a crime are tested by free and cued recall about their involvement in the crime shortly after exposure, and again 1 week later. On the first free and cued recall tests, one group of participants is instructed to feign amnesia by not remembering their involvement; a second group is asked to recall accurately; and a third group serves as a control condition and is not tested. One week later, all groups receive the same free and cued recall tests and are instructed to recall as accurately as possible. The results suggest that there are no effects of previously feigning amnesia on subsequent recall when participants are trying to remember accurately.

This conclusion, however, is premature because of methodological or data interpretation limitations in the previous research. First, some studies did not use the necessary delayed recall control condition (Christianson \& Bylin, 1999; Van Oorsouw \& Merckelbach, 2006). Second, a cued recall ceiling effect in one study made it difficult to determine whether feigning amnesia had any subsequent effect (Bylin \& Christianson, 2002). Third, some studies employed mock crimes involving students attacking dummies with pool cues and robbing bars that, although highly creative (see, e.g., Van Oorsouw \& Merckelbach, 2004, 2006), might be unrepresentative (hopefully) of the typical college experience. This is potentially troublesome, because if participants were unable to place themselves in the central role of previously published scenarios, then the effect of feigning amnesia - although easily demonstrated on initial recall 
tests - may not have been sufficiently strong to impair recall on the delayed tests. To more adequately determine whether feigning amnesia has any lingering effect on subsequent recall, it is necessary that one employ the methodologically appropriate three-group testing procedure with mock crime scenarios that are realistic for college students in the same research study. Accordingly, we used the appropriate design (together with realistic scenarios permitting greater identification of college students with the central character in the story) in two experiments of feigned amnesia. In both experiments, the central character of the story, described as "you," was drinking at a party, and this drinking led to a death.

\section{EXPERIMENT 1}

In the first experiment, college students read a narrative in which they were drinking at a party and, during the course of the party, they gave chicken bones to a dog, who then choked and died. If feigning amnesia impairs subsequent recall, then participants who previously feigned amnesia for details of the party should remember less on delayed recall tests when they are trying to remember accurately than should participants who previously recalled accurately and participants who recall accurately on the delayed tests for the first time. Alternatively, when all participants are trying to recall accurately on the delayed tests, if the feigned amnesia participants recall worse than do the accurate recall participants, but do not recall worse than the participants in the delayed recall control condition, the results would suggest that practice at remembering enhances free and cued recall, but that feigning amnesia has no effect on subsequent remembering.

\section{Method}

Participants. The participants were 60 Wesleyan University students - 23 males and 37 females between 17 and 23 years old - who received Introductory Psychology credit. None had taken part in any related memory research.

Materials. Participants read a typed, two-page story as they simultaneously listened to the same narrative spoken by a female voice on a Mac computer. The story contained 1,338 words, and its spoken duration was $7 \mathrm{~min}$. The narrative was embellished with numerous details, and the names of all people in the story were gender neutral (e.g., Sam could be Samantha or Samuel). Designed to represent a realistic aspect of college social life, the story involved a person, described as "you," who attended a team party the night after a college rugby game and, after much drinking, mistakenly gave a chicken bone to a puppy named "Ollie," who choked and died. The relevant portion of the larger narrative is reproduced below.

When you walk into the kitchen, you find it empty except for Ollie, who is curled up and sleeping in a little ball on his blue shag rug in the corner. Hearing you, he wakes up and leaps toward you, trying to play. You pick him up and he licks your face. When you put him down, he keeps jumping up trying to reach the counter. You realize he's trying to get at the pile of chicken bones that have been left on an aluminum platter next to the sink. Thinking, "dogs like bones," you pick the biggest one and give it to him, saying, "Here you go, Ollie. You'd better not tell Sam I gave this to you!' You look around for a cup, but all you see are empty beer cans, and a bowl of half-eaten soggy cornflakes. But then you see a stack of plastic red cups hidden behind a milk carton on the counter and you take one and fill it with tap water. Suddenly you hear strange noises coming from behind you. You turn around and realize that Ollie is choking. Worrying that the red collar around his neck is too tight and is choking him, you kneel down and loosen it. When this doesn't stop the choking, you realize that it could be that he's choking on the bone you just fed him, which is now nowhere in sight. Looking around, you realize there is no one around to help and the music is too loud to yell for someone's attention outside. You begin to panic and decide to try to get the bone out yourself. You try to fish out the bone, using your fingers to keep his mouth open and try to curl your finger around the bone, but instead, you end up pushing it back even further. Before you can think of what to do next, you hear the door open and realize a group of people from outside is coming into the kitchen. You hear them drunkenly singing "Total Eclipse of the Heart" from the hallway and you only have a few seconds to decide what to do. You panic and think "I better get out of here" and leave by the back door before the group comes into the kitchen. Too afraid to see anyone else, you decide to head back to your dorm.

Procedure. The participants were tested individually and were told that this experiment involved memory for a detailed, fictional story in which they needed to imagine themselves as the central character in the narrative. Before the story was presented, the participants were specifically told that they would be asked to recall what they remembered from the story. The participants were also told that they would hear the story as they simultaneously read it in order to help focus their attention and enhance their comprehension. An additional purpose of the auditory version was to ensure that all participants received the same narrative information by reading and listening for the same duration during study. After the story was simultaneously read and heard once, and before any memory testing, the participants performed a 10-min visual search distraction task that consisted of finding the names of male and female actors in blocks of letter arrays.

After the distraction task, the participants were randomly assigned to one of three different memory test conditions: a feigned amnesia recall, an accurate recall, or a delayed accurate recall condition. The feigned amnesia and accurate recall participants were tested immediately after the distraction task (Session 1) and again 1 week (6-8 days) later (Session 2); the delayed accurate recall participants were dismissed after the distraction task and were only tested after a 1-week delay (Session 2). Participants in each condition received the same two memory tests in the same order. A written free recall test was presented first, without time limit. The participants were given a lined sheet of paper $(8.5 \times 11 \mathrm{in}$.) and asked to describe in detail what happened between the time you left your friends to go into the kitchen and the time you left the party. We restricted the free recall test to the most critical portion of the story (approximately $28 \%$ of the narrative) in order to focus on the conditions surrounding the death of the dog and to limit the amount of material that participants were asked to recall. Following free recall, the participants were given a 37-item cued recall test about specific details of the night of the party (e.g., What time did you arrive at the party? What song did you hear your drunken friends singing?), and these questions covered the entire story. The cued recall questions were presented in the chronological order of the story, and they were presented in a single order. Participants were instructed to answer them in their order of presentation in test booklets.

Before the memory tests in Session 1, participants in the feigned amnesia condition (Group 1, $n=20$ ) were instructed to pretend that their memory for the night of the party was impaired by drinking. Specifically, these participants were instructed as follows:

At practice the following Monday, you find out that Ollie died choking on the bone. The team captain has figured-out that you were the last person in the kitchen before the puppy was found and calls you over after practice to ask what happened. You fear that answering honestly will ruin your relationship with the captain and the team. Therefore, in order to evade responsibil- 
ity, you decide to pretend that your drinking that night impaired your memory for the incident. When you are asked about the incident, you must respond in such a way that it looks like you have great difficulty remembering what happened.

Participants in the accurate recall condition (Group 2, $n=20$ ) were instructed to recall the incident as truthfully as possible in Session 1. They were instructed as follows:

At practice the following Monday, you find out that Ollie died choking on the bone. The team captain has figured-out that you were the last person in the kitchen before the puppy was found and calls you over after practice to ask what happened. You decide to tell the captain the truth.

Finally, participants in the delayed accurate recall condition (Group 3, $n=20$ ) did not receive any memory tests in Session 1. Because these participants served as a control condition to determine the effect of a delay on free and cued recall, they were only tested in Session 2.

In Session 2, the free recall and cued recall tests were repeated in the same order. However, for these memory tests, participants in all groups were instructed to recall the events of the night of the party as accurately as possible, even if they were previously instructed to fake amnesia. Upon completion of the experiment, all participants were fully debriefed.

\section{Results and Discussion}

The pertinent data for this experiment are the mean proportions of correct free recall, incorrect free recall (i.e., intrusion errors), and correct cued recall. Following Van Oorsouw and Merckelbach (2004), the proportion of correct free recall was based on the number of story elements recalled divided by the total number of elements in the relevant portion of the story. Two of the experimenters independently identified 39 critical elements in the story that occurred after the central character entered the kitchen. A critical element was defined as information that represented a main idea for understanding the narrative sequence (e.g., When you turned around, you realized that Ollie was choking). Each recalled element was worth 1 point. An incorrect free recall proportion was based on the number of intrusion errors recalled divided by the total number of story elements (correct and incorrect) recalled for each participant. Finally, the proportion of correct cued recall was based on the number of cued recall questions answered correctly divided by the number of questions. Each of the 37 questions on the cued recall test was worth 1 point. The same scoring procedures were used for participants in each group, and the above three proportions were determined individually for each participant and combined for each group. They are presented in Table 1.

Free recall. Table 1 shows that participants who were instructed to feign amnesia (Group 1: Amnesia-Accurate) demonstrated less correct free recall and more incorrect free recall than did participants who had been told to recall accurately (Group 2: Accurate-Accurate) when tested immediately after study (Test 1). One week later, participants who had previously faked amnesia showed an increase in correct recall and a decrease in false recall when asked to recall accurately (Test 2). However, their recall on Test 2 was basically the same as that of the participants in the delayed accurate condition (Group 3: No Recall-Accurate)
Table 1

Mean Proportions of Items Recalled in Experiment 1

\begin{tabular}{lcc}
\hline \multicolumn{1}{c}{$\begin{array}{c}\text { Recall Instructions } \\
\text { and Test Format }\end{array}$} & \multicolumn{2}{c}{ Memory Tests } \\
\cline { 2 - 3 } & Test 1 & Test 2 \\
\hline Group 1 (T1, Amnesia; T2, Accurate) & & \\
$\quad$ Correct free recall & .08 & .27 \\
$\quad$ Incorrect free recall & .32 & .05 \\
$\quad$ Correct cued recall & .52 & .67 \\
Group 2 (T1, Accurate; T2, Accurate) & & \\
$\quad$ Correct free recall & .45 & .40 \\
$\quad$ Incorrect free recall & .01 & .04 \\
$\quad$ Correct cued recall & .84 & .78 \\
Group 3: (T1, No recall; T2, Accurate) & & \\
$\quad$ Correct free recall & - & .25 \\
$\quad$ Incorrect free recall & - & .08 \\
Correct cued recall & - & .53 \\
\hline
\end{tabular}

and, at least for correct free recall, still worse than that of participants who had recalled accurately on both tests.

These results were supported by separate ANOVAs on correct and incorrect free recall for participants in Groups 1 and 2 for Tests 1 and 2, and correct and incorrect free recall for Groups 1, 2, and 3 for Test 2. Comparing Groups 1 (Amnesia-Accurate) and 2 (Accurate-Accurate) over Tests 1 and 2 for correct recall, there were significant effects of groups, with Group 1 having lower recall than Group 2 (.17 vs. .43) $\left[F(1,38)=98.37, M S_{\mathrm{e}}=1.31, p<\right.$ $.0001]$; of tests, with recall lower on Test 1 than on Test 2 $(.27$ vs. .34$)\left[F(1,38)=43.92, M S_{\mathrm{e}}=.10, p<.0001\right]$; and an interaction of these variables $\left[F(1,38)=124.40, M S_{\mathrm{e}}=\right.$ $.29, p<.0001]$. As indicated in Table 1, Group 2 produced more correct free recall than did Group 1 on Test 1 (.45 vs. $.08)\left[F(1,38)=184.51, M S_{\mathrm{e}}=.01, p<.0001 ;\right.$ and Test 2 $(.40$ vs. .27$)\left[F(1,38)=22.98, M S_{\mathrm{e}}=.01, p<.0001\right]$. Group 1 showed an increase in correct recall from Test 1 to Test $2\left(.08\right.$ vs. .27) $\left[F(1,38)=158.08, M S_{\mathrm{e}}=.01, p<\right.$ $.0001]$, whereas Group 2 showed a decrease (.45 vs. .40) $\left[F(1,38)=10.24, M S_{\mathrm{e}}=.01, p<.01\right]$.

These variables also influenced incorrect free recall. There were effects of groups, with Group 1 producing more intrusions than Group $2(.19$ vs. .03) $[F(1,38)=$ $\left.42.33, M S_{\mathrm{e}}=.51, p<.0001\right]$, and of test, with more intrusions on Test 1 than on Test $2(.17$ vs. .05) $[F(1,38)=$ $\left.22.44, M S_{\mathrm{e}}=.29, p<.0001\right]$, and there was an interaction of both variables $\left[F(1,38)=34.16, M S_{\mathrm{e}}=.02, p<\right.$ .0001]. Group 1 (Amnesia-Accurate) produced more intrusions than did Group 2 (Accurate-Accurate) on Test 1 $(.32$ vs. .01$)\left[F(1,38)=43.86, M S_{\mathrm{e}}=.51, p<.0001\right]$, but not on Test $2(.05$ vs. .04, $p>.40)$. Finally, the decrease in intrusions from Test 1 to Test 2 was significant for Group 1 (.32 vs. .05) $\left[F(1,38)=55.98, M S_{\mathrm{e}}=.01\right.$, $p<.0001]$. Even though participants in the feigned amnesia group were instructed to demonstrate great difficulty remembering what happened in the initial free recall test, they made both commission (intrusions) and omission errors. Intrusion errors following similar instructions were also observed by Van Oorsouw and Merckelbach (2004).

An analysis of all three groups (Group 1, AmnesiaAccurate; Group 2, Accurate-Accurate; and Group 3, No Recall-Accurate) on Test 2 (the only test given to the 
delayed accurate recall condition) revealed a significant group effect in correct free recall $\left[F(2,57)=19.93, M S_{\mathrm{e}}=\right.$ $.14, p<.0001]$. Newman-Keuls comparisons showed that Groups $1(.27)$ and $3(.25)$ did not differ $(p>.05)$, and both were lower on Test 2 than was Group 2 (.40) (both $p \mathrm{~s}<.01)$. An analysis of incorrect free recall on Test 2 showed no effect of group on intrusions $(p>.50)$.

Cued recall. A similar pattern of results was observed for cued recall. As shown in Table 1, participants who had been instructed to recall accurately on Test 1 answered more cued recall questions correctly than did participants who had been instructed to feign amnesia. On Test 2, when all participants tried to answer correctly, this difference was greatly reduced. An ANOVA revealed effects of groups, with Group 1 showing lower cued recall than did Group 2 (.60 vs. .81) $\left[F(1,38)=42.65, M S_{\mathrm{e}}=.90, p<\right.$ $.0001]$, and of tests, with performance lower on Test 1 than on Test $2\left(.68\right.$ vs. .72) $\left[F(1,38)=6.17, M S_{\mathrm{e}}=.04, p<\right.$ $.05]$, and an interaction of groups and tests $[F(1,38)=$ $\left.31.55, M S_{\mathrm{e}}=.22, p<.0001\right]$. Although Group 2 produced greater cued recall than did Group 1 on both tests (both $p \mathrm{~s}<01$ ), Group 1 showed an increase from Test 1 to Test 2 (.52 vs. .67) $\left[F(1,38)=32.81, M S_{\mathrm{e}}=.01, p<\right.$ $.0001]$, whereas Group 2 showed only a marginal decrease over tests (.84 vs. .78) $(p>.05)$. A comparison of all three groups (Group 1: Amnesia-Accurate, Group 2: Accurate-Accurate, and Group 3: No Recall-Accurate) for correct cued recall only on Test 2 again revealed an effect of groups $\left[F(2,57)=29.79, M S_{\mathrm{e}}=.31, p<.0001\right]$, with Newman-Keuls comparisons showing Group $2(.78)$ higher than Groups 1 (.67) and $3(.53)$ (both $p$ s $<.01)$, and Group 1 higher than Group $3(p<.01)$.

Together, these data indicate that instructions to feign amnesia decreased both free recall and cued recall and, during free recall, they led to more intrusion errors than did instructions to recall accurately on the immediate memory tests. The increase in intrusion errors, which followed specific instructions to respond in such a way that it looks like you have great difficulty remembering what happened, suggests that these participants were actively engaged in feigning amnesia, even though they may have had their own ideas about what the instructions meant. After a retention interval of 1 week, participants who had previously feigned amnesia were able to increase their correct free and cued recall and to decrease their intrusions in free recall, but their correct free and cued recall levels did not match those of participants who had recalled accurately on both tests. More importantly, participants who had previously feigned amnesia showed better, not worse, correct cued recall than did participants in the delayed accurate recall condition (.67 vs. .53), and they were not worse on correct free recall (.27 vs. .25). Whether measured by free or cued recall, these results provide no evidence that feigning amnesia impairs subsequent memory performance. Accurately recalling a detailed narrative twice over time enhances both free and cued recall performance, in comparison with a control condition of only delayed recall. However, in comparison with this same control condition, feigning amnesia does not impair later performance when participants attempt to recall accurately.

\section{EXPERIMENT 2}

To determine the reliability of the results from the first experiment, we conducted a second study with the same three-group procedure that involved a different narrative that should also have been realistic to college students. The hypotheses that were tested remained the same.

\section{Method}

Participants. The participants were 46 additional Wesleyan University students - 20 males and 26 females between 17 and 23 years old - who received Introductory Psychology credit. None had taken part in any related memory research.

Materials. In this experiment, the participants listened to a new narrative spoken by a female voice on a Mac computer. This story contained 1,557 words, and its spoken duration was $7.5 \mathrm{~min}$. As in the first experiment, this story was designed to represent a realistic aspect of college social life in which the gender-neutral central character in the story-described as "you"- threw a party one night for friends. However, in this narrative, after much drinking, you mistakenly gave food containing peanuts to a friend named "Jaime," who subsequently died due to a peanut allergy. The relevant portion of this narrative is reproduced below.

Soon, everyone has dispersed except for you and Jaime, a sophomore you've been introduced to a few times. "Hey, how are you doing?"You realize you're slurring slightly, but at this point there's nothing you can do. "Not badly, we haven't talked too much before. Do you do this often?" smiles Jaime. "Uh, what?" you have a hard time concentrating on Jaime's polite chitchat. Now your focus has shifted away from this awkward conversation and toward the refrigerator. "Let's get going," Jaime breaks in. "I want to get done early enough to go to the Late Night Café before it closes." Jaime's comment reminds you of your halfeaten pesto in the fridge. Your stomach begins to grumble. "Just a sec. I'm starving, let me grab something to eat," you say. You step on a few carelessly discarded beer cans as you make your way to the mini-fridge. Taking out your pasta, you cram some forkfuls into your mouth before you remember your manners. You turn to Jaime. "You want in on this?" you ask, holding out your fork. Jaime eyes the pasta hungrily. "Does it have nuts in it? I'm allergic." You examine the dish closely. "Green . . . Yellow ... Nah, doesn't look like it has nuts. No, you're fine," you say. "You sure?" "Yeah, it's delicious, it's good for you. Just eat it, if you don't like it you can stop by the falafel cart later." Jaime considers. "Well ... I guess I could save the points. That new late-night menu is ridiculously expensive." Jaime graciously accepts and the two of you clear the plate in seconds.

Procedure. The overall procedure employed in the first experiment was followed in this experiment, with two notable exceptions during study, and one at test. First, a new story was presented. Second, because this story was longer than the one used in the first experiment, the participants read and simultaneously listened to this story twice during study, with a 1-min break before repetition, to enhance comprehension and memory of the story content. Finally, after the memory tests were completed, all participants answered a short questionnaire to assess the impact and realism of the story. All other study and distraction procedures were the same as in Experiment 1.

For Experiment 2, there were 14 participants in the feigned amnesia condition (Group 1), 16 participants in the accurate recall condition (Group 2), and 16 participants in the delayed accurate recall condition (Group 3). Memory testing followed the same format as before, with free recall followed by cued recall in Sessions 1 and 2 for the feigned amnesia and accurate recall conditions, and in Session 2 only for the delayed accurate recall condition. Before the memory tests in Session 1, participants in the feigned amnesia condition were again instructed to pretend that drinking impaired their memory for the night of the party. But, in this experiment, these 
participants were told to imagine that their dean was questioning them the day after the party and that they should feign amnesia by not being able to remember events from the previous night. Specifically, the dean wanted to know what had happened between the time you started drinking and the time you went back to your dorm room. This critical portion of the story (approximately $48 \%$ of the narrative) focused on the death of Jaime and helped limit the amount of material to be recalled. These participants were instructed as follows for the written free recall test:

Imagine that your class dean is questioning you about Jaime's death. It is the afternoon after the night of partying and you are sitting in the dean's office. You decide that if you answer honestly, you could be held responsible for Jaime's death. This might mean being sued by your friend's family or expulsion from college. Because you were drinking at the party, you decide to fake amnesia and claim that you can't remember anything about that night after you started drinking. Imagine that you are reporting this information to your dean, and report it in a way that allows you to evade any responsibility for the death due to your being unable to remember because of drinking.

Participants in the accurate recall condition were told to recall the incident as accurately as possible in Session 1. These participants were given the following instructions:

Imagine that your class dean is questioning you about Jaime's death. It is the afternoon after the night of partying and you are sitting in the dean's office. You decide that honesty is the best policy, so you tell the dean the truth.

As in the first experiment, participants in the delayed accurate recall condition were only tested in Session 2.

Following free recall, the participants in the feigned amnesia and accurate recall groups were given a cued recall test that contained 30 questions about specific details from the entire narrative, arranged in chronological order. In Session 2, the free recall and cued recall tests were repeated in the same order as before, and participants in all groups were instructed to recall the events of the night of the party as accurately as possible, even if they had been previously instructed to feign amnesia. All other aspects of the free and cued recall tests were the same as those in the first experiment.

Finally, to gauge how participants were influenced by the story, all participants completed a short questionnaire using a 7-point scale, where $1=$ not at all and $7=$ to a very high degree, that included these questions:

1. To what degree were you emotionally influenced by the story?

2. To what degree were you able to picture yourself as the "you" in the story?

3. How realistic do you think the story was?

These questions were answered after the memory tests were completed in Sessions 1 and 2.

\section{Results and Discussion}

As in the first experiment, the important data are the mean proportions of correct free recall, incorrect free recall, and correct cued recall, and they were calculated in the same manner as before. Three of the experimenters independently identified 18 critical elements in the story that occurred after people arrived for the party. A critical element was defined as information that was necessary for understanding the narrative sequence in terms of clarity and continuity (e.g., Jaime asked you if the pesto had nuts in it). Each recalled element was worth 1 point. An incorrect free recall proportion was again based on the number of incorrect elements recalled (intrusion errors) divided by the total number of story elements (correct and incorrect) recalled for each participant, and the proportion of correct cued recall was based on the number of cued recall questions answered correctly divided by the number of questions. Each of the 30 questions was worth 1 point. Again, the same scoring procedures were used for participants in each group, and the three proportions were individually determined for each participant and combined for each group. The proportions for correct and incorrect free recall and correct cued recall are presented in Table 2.

Free recall. Table 2 shows that when participants were tested immediately after study (Test 1 ), those participants who had been instructed to feign amnesia (Group 1) produced less correct free recall and more intrusion errors than did participants who had tried to recall accurately (Group 2). On the delayed tests 1 week later (Test 2), participants who previously faked amnesia increased their correct recall and decreased their intrusions when they tried to recall accurately, but their recall on Test 2 was essentially the same as that of the participants in the delayed accurate condition (Group 3), and still worse than that of participants in Group 2.

Separate ANOVAs on correct and incorrect free recall for participants in Groups 1 (Amnesia-Accurate) and 2 (Accurate-Accurate) for Tests 1 and 2 and correct and incorrect free recall for Groups 1, 2, and 3 for Test 2 supported these observations. In comparing Groups 1 and 2 over Tests 1 and 2 for correct recall, there were significant effects of groups, with Group 1 having lower recall than did Group 2 (.41 vs. .66) $\left[F(1,28)=32.47, M S_{\mathrm{e}}=.90\right.$, $p<.0001]$; of tests, with recall lower on Test 1 than on Test $2\left(.48\right.$ vs. .60) $\left[F(1,28)=16.00, M S_{\mathrm{e}}=.22, p<\right.$ $.001]$; and an interaction of these variables $[F(1,28)=$ $\left.24.11, M S_{\mathrm{e}}=.34, p<.0001\right]$. Table 2 shows that Group 2 produced more correct free recall than did Group 1 on Test $1\left(.68\right.$ vs. .28) $\left[F(1,28)=63.48, M S_{\mathrm{e}}=.02, p<\right.$ $.0001]$, but not on Test 2 (.65 vs. .56) $[F(1,28)=2.93$, $\left.M S_{\mathrm{e}}=.02, p>.05\right]$. Group 1 showed an increase in correct recall from Test 1 to Test $2(.28$ vs. .56) $[F(1,28)=$ $\left.37.23, M S_{\mathrm{e}}=.01, p<.0001\right]$, whereas Group 2 showed a minor decrease (.68 vs. .65) $(p>.50)$.

These variables also influenced incorrect free recall in the same manner as in Experiment 1, although high

Table 2

Mean Proportions of Items Recalled in Experiment 2

\begin{tabular}{llc}
\hline \multirow{2}{*}{$\begin{array}{c}\text { Recall Instructions } \\
\text { and Test Format }\end{array}$} & \multicolumn{2}{c}{ Memory Tests } \\
\cline { 2 - 3 } & Test 1 & Test 2 \\
\hline Group 1 (T1, Amnesia; T2, Accurate) & .28 & .56 \\
$\quad$ Correct free recall & .43 & .04 \\
$\quad$ Incorrect free recall & .63 & .77 \\
$\quad$ Correct cued recall & & \\
Group 2 (T1, Accurate; T2, Accurate) & .68 & .65 \\
$\quad$ Correct free recall & .02 & .05 \\
$\quad$ Incorrect free recall & .87 & .83 \\
Correct cued recall & & \\
Group 3: (T1, No recall; T2, Accurate) & - & .60 \\
$\quad$ Correct free recall & - & .09 \\
$\quad$ Incorrect free recall & - & .67 \\
Correct cued recall & & \\
\hline
\end{tabular}


variability masked the apparent effects of groups and tests. Although Group 1 produced more intrusions than did Group 2 (.23 vs. .04), and there were more intrusions on Test 1 than on Test 2 (.17 vs. .05), neither effect was significant $(p>.10)$. There was a weak interaction of these variables $\left[F(1,28)=3.58, M S_{\mathrm{e}}=.66, p<.07\right]$; Group 1 produced more intrusions on Test 1 than on Test 2 $(.43$ vs. .04$)\left[F(1,28)=5.87, M S_{\mathrm{e}}=.18, p<.05\right]$. No other simple effects reached significance $(p>.05)$.

Analyses of groups (Group 1, Amnesia-Accurate; Group 2, Accurate-Accurate; and Group 3, No RecallAccurate) on Test 2 revealed no significant difference between Groups 1, 2, and 3 in correct free recall $(.56, .65$, and .60, respectively; $p>.20$ ) or incorrect free recall (.04, .05 , and $.09, p>.10$ ). For these analyses, the important point is that participants in Group 1 who had previously feigned amnesia did not produce lower free recall than did participants in Group 3, who had recalled the story for the first time.

Cued recall. The cued recall results produced essentially the same pattern of results as did the first experiment. Participants who had tried to recall accurately on Test 1 had higher correct cued recall than did participants who had been instructed to feign amnesia; on Test 2, when all participants tried to answer accurately, this difference was diminished. Analyses revealed a main effect of groups, with Group 1 showing lower correct cued recall than did Group 2 (.70 vs. .85) $\left[F(1,28)=43.30, M S_{\mathrm{e}}=.34, p<\right.$ $.0001]$; of tests, with performance lower on Test 1 than on Test $2\left(.75\right.$ vs. .80) $\left[F(1,28)=6.07, M S_{\mathrm{e}}=.04, p<.05\right]$; and an interaction of groups and tests $[F(1,28)=17.87$, $\left.M S_{\mathrm{e}}=.11, p<.001\right]$. Group 2 produced greater cued recall than did Group 1 on Test $1(.87$ vs. .63) $(p<0001)$ and Test 2 (.83 vs. .77) $(p<.05)$, with Group 1 showing an increase in cued recall accuracy from Test 1 to Test 2 (.63 vs. $.77)\left[F(1,28)=20.98, M S_{\mathrm{e}}=.01, p<.0001\right]$ and Group 2 showing a minor decrease over tests $(.87$ vs. .83) $(p>.20)$. A comparison of all three groups on Test 2 for correct cued recall revealed an effect of groups $\left[F(2,43)=6.92, M S_{\mathrm{e}}=\right.$ $.09, p<.005]$, with Newman-Keuls comparisons showing Group $2(.83)$ higher than Groups $1(.77)$ and $3(.67)$ (both $p$ s $<.05$ ), and no difference between Groups 1 and 3 $(p>.05)$. Once again, when compared with Group 3 (the appropriate control condition), Group 1 showed no effect of previously feigning amnesia on subsequent cued recall.

Finally, Table 3 presents the mean ratings for the three questions asked about story impact and realism at the end of the test sessions. Mean ratings were at or above the midpoint of the 7-point scale for each question and each test. In general, all participants were moderately influenced by the story emotionally, and they were able to picture themselves as the central character in the story. This finding is important, because it demonstrates that our mock crime scenario was not perceived as unrealistic for college students in this study. Uniformly higher ratings were obtained from all participants for the question about story realism. For this question, all mean ratings were above the scale midpoint. These findings were supported by a mixed ANOVA that compared the mean ratings of Groups 1 and 2 for both test sessions and three questions. The main ef- fect of questions was significant $\left[F(2,56)=9.72, M S_{\mathrm{e}}=\right.$ $22.87, p<.001]$, but there were no other main effects or interactions (all $p \mathrm{~s}>.20$ ). Newman-Keuls comparisons showed that the mean rating for Question 3 (5.27) was higher than the ratings for either Question 1 (4.26) or Question 2 (4.15) (both $p s<.01$ ), and that the ratings for Questions 1 and 2 did not differ $(p>.05)$. The same outcome was observed when all three groups were compared on the questionnaire results after Test 2 . There was a significant effect of questions $\left[F(2,86)=9.61, M S_{\mathrm{e}}=13.43\right.$, $p<.001]$, and no effect of groups or a group $\times$ question interaction (both $p \mathrm{~s}>.45$ ). Question 3 (5.23) was rated higher than Questions 1 (4.38) and 2 (4.22) (both $p$ s $<$ $.01)$, and Questions 1 and 2 did not differ $(p>.05)$.

In summary, this study showed that previously feigning amnesia had little effect on the subsequent free or cued recall of a story when participants attempted to recall accurately. This result indicates that our findings from the first study are reliable. In addition, a comparison of the results shown in Tables 1 and 2 indicates that although the same pattern of results was obtained in both studies, the correct free and cued recall proportions were higher in this experiment than in the first experiment. This difference may be explained by a procedural difference between experiments. Participants in this experiment received two presentations of the story during study, whereas they received a single story presentation in the prior experiment. Finally, the participants in all conditions of this study rated this story as being realistic in terms of college social life. We will address the implications of these findings in the next section.

\section{GENERAL DISCUSSION}

We demonstrated the same results in two experiments. On immediate memory tests, instructions to feign amnesia (Group 1) decreased both free recall and cued recall and led to more intrusion errors during free recall than did instructions to recall accurately (Group 2). On delayed memory tests, when all participants tried to recall accurately, the participants who had previously feigned amnesia increased their correct free recall and cued recall and

Table 3

Mean Ratings on Questionnaire in Experiment 2

\begin{tabular}{cccc}
\hline \multirow{2}{*}{$\begin{array}{c}\text { Recall Instructions } \\
\text { and Test Format }\end{array}$} & \multicolumn{3}{c}{ Postexperiment Questions } \\
\cline { 2 - 4 } & 1 & 2 & 3 \\
\hline Group 1 & 4.71 & 3.93 & 5.21 \\
Test 1: Amnesia & 4.21 & 3.79 & 5.00 \\
Test 2: Accurate & & & \\
Group 2 & 3.94 & 4.50 & 5.44 \\
Test 1: Accurate & 4.19 & 4.38 & 5.44 \\
Test 2: Accurate & & & \\
Group 3 & - & - & - \\
Test 1: No recall & 4.75 & 4.50 & 5.25 \\
Test 2: Accurate &
\end{tabular}

Note-Mean ratings based on a 7-point scale, where $1=$ not at all and 7 = to a very high degree. Q1: To what degree were you emotionally influenced by the story? Q2: To what degree were you able to picture yourself as the "you" in the story? Q3: How realistic do you think the story was? 
decreased their free recall intrusions, but their correct recall levels did not match those of the participants who had recalled accurately at both times. Moreover, when the participants who had previously feigned amnesia (Group 1) tried to recall accurately on the delayed tests, their performance was not worse than that of the control participants who had only received the delayed tests (Group 3). In both experiments, Groups 1 (Amnesia-Accurate) and 3 (No Recall-Accurate) performed similarly on delayed correct free recall, and Group 1 was, in fact, better than Group 3 on delayed correct cued recall.

The comparisons of Groups 1 and 3 provide no support for the hypothesis that feigning amnesia impairs subsequent memory performance when participants are tested by free or cued recall. Recalling details from a story accurately on both immediate and delayed tests enhances free and cued recall performance as compared with a control condition that tested only delayed recall. But, in comparision with this same control condition, feigning amnesia on an immediate test does not impair later recall when these participants attempt to recall accurately. On the basis of these findings, there was no "feigned amnesia effect" involving memory suppression or memory inhibitory processes that hampered later recall. No evidence was found for any memory impairment. Rather, the effect of employing feigned amnesia instructions appears to be methodological. The most parsimonious interpretation of our results is that feigning amnesia instructions impose limits on the opportunity for participants to recall information correctly from memory. Specifically, participants who are instructed to feign amnesia on immediate tests before being instructed to recall accurately on delayed tests have less practice at recalling accurately than do participants who are told to recall accurately at both times. Thus, we propose that participants in Group 1 (Amnesia-Accurate) performed worse than did participants in Group 2 (Accurate-Accurate) on the delayed free and cued recall tests because Group 1 had less practice at recalling the facts of a story correctly than did Group 2 . As previous research has demonstrated, recall repetition enhances accuracy (Mulligan, 2005),

This same recall practice interpretation can account for the performance of Groups 1 (Amnesia-Accurate) and 3 (No Recall-Accurate) on the delayed free recall and cued recall tests. In the present experiments, we limited the amount of information requested for free recall in order to make the amount to be recalled manageable and to focus the recall on the details surrounding the death of a character. Thus, although participants were asked to free recall only the critical portion of a story, they were tested by cued recall over an entire story. To the extent that participants in the feigned amnesia group followed the instructions for the immediate tests (i.e., they faked amnesia for the critical portion of the story), these participants accurately free recalled the critical portion only one time on the delayed test, just as participants in the delayed accurate recall group did. Thus, the recall practice hypothesis suggests that free recall performance of Groups 1 and 3 would be similar on the delayed free recall test, and this outcome was observed in both experiments.
But, according to this hypothesis, why would correct cued recall vary between the three groups on the delayed test? In two experiments, we found that Group 2 (Accurate-Accurate) produced higher cued recall than did Group 1 (Amnesia-Accurate), and Group 1 produced higher cued recall than did Group 3 (No Recall-Accurate) on the delayed cued recall test. Because the cued recall test consisted of questions from all portions of a story, not just the critical portion, the recall practice hypothesis can accommodate these group differences in cued recall. Specifically, in our procedure, participants in Group 1 were instructed to feign amnesia on the immediate free and cued recall tests for only the critical portion of a story that dealt with a death, not for the entire story. We used this procedure because we needed to ensure that all participants would be engaged in the free and cued recall tests. If, for example, we had instructed participants to feign amnesia for an entire story, these participants might not be engaged in the recall tests if they stated that they could not remember anything and they left the cued recall questions blank. Our procedure ensured engagement by all participants in the recall tests. Consequently, this procedure produced differential recall practice for the three groups on the delayed cued recall test. Participants in the accurate recall condition (Group 2) attempted to answer all of the cued recall questions accurately twice; participants in the feigned amnesia condition (Group 1) tried to answer only a portion of those questions accurately twice (questions not involving details of a death), and participants in the delayed accurate recall condition (Group 3) attempted to answer the cued recall questions accurately just once. Thus, in terms of the recall practice hypothesis, participants in Group 2 received more cued recall practice than did participants in Group 1, who in turn received more practice than did participants in Group 3, and this difference in recalling details of the story is consistent with the particular pattern of group differences in cued recall found in both experiments.

Overall, the pattern of free and cued recall results that we observed is similar to that observed in previous studies of feigned amnesia (Bylin \& Christianson, 2002; Christianson \& Bylin, 1999; Van Oorsouw \& Merckelbach, 2004, 2006). However, our research extends the study of feigned amnesia by consistently employing the appropriate control group and using story narratives that are realistic for college student participants. Moreover, whereas Christianson and Bylin (1999) first suggested the recall practice hypothesis, their lack of the appropriate delayed accurate recall condition did not permit this hypothesis to be tested. Follow-up studies by Bylin and Christianson (2002) and Van Oorsouw and Merckelbach (2004) included the appropriate control group, but a ceiling effect obscured a possible group difference in Bylin and Christianson's study, and Van Oorsouw and Merckelbach used an unrealistic mock crime that involved college students killing someone with a pool cue. Still, even though the overall pattern of results in these studies favored an interpretation of any feigned amnesia impairment in terms of differential recall, that interpretation has not been sufficiently advocated. Van Oorsouw and Merckelbach (2004), 
for example, stated that their research "supports the idea that simulating amnesia in order to evade responsibility for a crime has detrimental effects on true memory for the crime. Our results also suggest that this effect can best be understood in terms of lack of rehearsal" (p. 505). We agree strongly with their second statement, and, on the basis of parsimony, we suggest that - at least under the experimental conditions tested to date - there is no "feigned amnesia effect" other than differential practice at recall.

In closing, we note that our research and other studies that have employed similar procedures to examine the possible consequences of feigning amnesia suffer from an important inherent limitation. This research has attempted to create an experimental analogue of focal retrograde amnesia, whereby defendants claim amnesia for a crime. As Schacter (1986) previously noted, we cannot know if these experimental results can generalize to actual cases. However, to the extent that laboratory procedures can successfully capture the processes underlying human memory performance, the laboratory studies of feigned amnesia suggest that faking amnesia for a crime will not impair a person's memory for that crime when that person later seeks to remember it accurately. Research has already demonstrated that conscious suppression of information in memory is difficult to achieve (Bulevich, Roediger, Balota, \& Butler, 2006), that attempts at thought suppression can paradoxically enhance thought accessibility (Wegner, 1994), and that lying may strengthen, rather than distort, the truth (Polage, 2004).

\section{AUTHOR NOTE}

A Wesleyan University Faculty Grant in Support of Scholarship given to J.G.S. supported this research. Address correspondence to J. G. Seamon, Psychology Department, Wesleyan University, Middletown, CT 06459 (e-mail: jseamon@wesleyan.edu).

\section{REFERENCES}

Bernard, L. C., McGrath, M. J., \& Houston, W. (1994). Discriminating between simulated malingering and closed head injury on the Wechsler Memory Scale-Revised. Archives of Clinical Neuropsychology, 8, 539-551.
Bulevich, J. B., Roediger, H. L., III, Balota, D. A., \& Butler, A. C. (2006). Failures to find suppression of episodic memories in the think/ no-think paradigm. Memory \& Cognition, 34, 1569-1577.

Bylin, S., \& Christianson, S.-A. (2002). Characteristics of malingered amnesia: Consequences of withholding vs. distorting information on later memory of a crime event. Legal \& Criminological Psychology, 7, 45-61.

Cercy, S. P., Schretlen, D. J., \& Brandt, J. (1997). Simulated amnesia and the pseudo-memory phenomena. In R. Rogers (Ed.), Clinical assessment of malingering and deception (2nd ed., pp. 85-107). New York: Guilford Press.

Christianson, S.-A., \& Bylin, S. (1999). Does simulating amnesia mediate genuine forgetting for a crime event? Applied Cognitive Psychology, 13, 495-511.

Greiffenstein, M. F., BAKer, W. J., \& Gola, T. (1994). Validation of malingered amnesia measures with a large clinical sample. Psychological Assessment, 6, 218-224.

Jelicic, M., Merckelbach, H., \& Van Bergen, S. (2004). Symptom validity testing of feigned amnesia for a mock crime. Archives of Clinical Neuropsychology, 19, 525-531.

Kopelman, M. D. (1995). The assessment of psychogenic amnesia In A. D. Baddeley, B. A. Wilson, \& F. N. Watts (Eds.), Handbook of memory disorders (pp. 427-448). New York: Wiley.

Mulligan, N. W. (2005). Total retrieval time and hypermnesia: Investigating the benefits of multiple recall tests. Psychological Research, 69, 272-284.

Polage, D. C. (2004). Fabrication deflation? The mixed effects of lying on memory. Applied Cognitive Psychology, 18, 455-465.

Pyszora, N. M., Barker, A. F., \& Kopelman, M. D. (2003). Amnesia for criminal offences: A study of life sentence prisoners. Journal of Forensic Psychiatry \& Psychology, 14, 475-490.

Rubinsky, E. W., \& BrandT, J. (1986). Amnesia and criminal law: A clinical overview. Behavioral Sciences \& the Law, 4, 27-46.

SCHACTER, D. L. (1986). Amnesia and crime: How much do we really know? American Psychologist, 41, 286-295.

VAN OORSOUw, K., \& MercKelbach, H. (2004). Feigning amnesia undermines memory for a mock crime. Applied Cognitive Psychology, 18, 505-518.

Van Oorsouw, K., \& Merckelbach, H. (2006). Simulating amnesia and memories of a mock crime. Psychology, Crime, \& Law, 12, 261-271.

Wegner, D. M. (1994). Ironic processes of mental control. Psychological Review, 101, 34-52.

Wiggins, E. C., \& BRANDT, J. (1988). The detection of simulated amnesia. Law \& Human Behavior, 12, 57-78.

(Manuscript received July 22, 2008; revision accepted for publication September 15, 2008.) 